\title{
Níveis de degradação das terras no município de Taperoá, Paraíba
}

O município de Taperoá localiza-se na região central do Estado da Paraíba, Mesorregião Borborema e Microrregião do Cariri Ocidental. O município está incluído na área geográfica de abrangência do semiárido do Brasil, tendo como critérios o índice pluviométrico, o índice de aridez e o risco a seca. Esta pesquisa está centrada no estudo da degradação ambiental no município de Taperoá - Paraíba, levando em consideração os limites geográficos que fica em torno da sub-bacia do rio, sendo ao norte, Areia de Baraúna, Salgadinho e Assunção, ao leste, Santo André e São José dos Cordeiros, ao sul, São José dos Cordeiros e Livramento, e ao oeste, Cacimbas e Passagem. Foram utilizados recursos disponíveis através das técnicas de geoprocessamento. O objetivo geral da pesquisa é analisar os níveis de degradação a partir de um estudo espaço temporal da cobertura vegetal, degradação das terras, além das vulnerabilidades da região, sendo elas social, econômica, tecnológica, ambiental e de susceptibilidade as estiagens. Para atender tais objetivos, foram realizados estudos comparativos dos anos de 1990 e 2015 , dentro dos limites geográficos apresentados. Os resultados em relação aos níveis de degradação das terras, houve redução nos níveis de degradação baixa e moderado baixa $(6,4 \mathrm{~km} 2 ; 72,0 \mathrm{~km} 2)$, o que apresenta uma redução nas áreas mais preservadas da região. No entanto, o nível degradação moderada teve aumento significativo (116 km2), este avanço no processo de degradação é consequência do desmatamento para diversos fins.

Palavras-chave: Cobertura vegetal; Degradação dos solos; Risco.

\section{Land degradation levels in the municipality of Taperoá, Paraíba}

The municipality of Taperoá is located in the central region of the State of Paraiba, Mesoregion Borborema and Microregion of Western Cariri. The municipality is included in the geographic area of coverage of the semiarid region of Brazil, having as criteria the rainfall index, the aridity index and the risk of drought. This research is centered on the study of environmental degradation in the municipality of Taperoá - Paraiba, taking into account the geographic limits around the subbasin of the river, in the north, Areia de Baraúna, Salgadinho and Assunção, in the east, Santo André and São José dos Cordeiros, to the south, São José dos Cordeiros and Livramento, and to the west, Cacimbas and Passagem. Resources available through geoprocessing techniques were used. The general objective of the research is to analyze the levels of degradation from a space-time study of vegetation cover, land degradation, in addition to the region's vulnerabilities, which are social, economic, technological, environmental and susceptibility to droughts. To meet these objectives, comparative studies were carried out for the years 1990 and 2015, within the geographic limits presented. The results in relation to the levels of land degradation, there was a reduction in the levels of low and moderate low degradation $(6.4 \mathrm{~km} 2 ; 72.0 \mathrm{~km} 2)$, which shows a reduction in the most preserved areas in the region. However, the moderate degradation level had a significant increase $(116 \mathrm{~km} 2)$, this advance in the degradation process is a consequence of deforestation for various purposes.

Keywords: Vegetal cover; Soil degradation; Risk

Topic: Engenharia Agrícola

Reviewed anonymously in the process of blind peer.
Received: 02/04/2021

Approved: $27 / 04 / 2021$
Júlia Soares Pereira itis

Universidade Federal de Campina Grande, Brasil http://lattes.cnpq.br/8908354485683197

http://orcid.org/0000-0002-6495-1169 julia eng@hotmail.com

\section{João Miguel de Moraes Neto (iD)}

Universidade Federal de Campina Grande, Brasil

http://lattes.cnpq.br/3720844263112296

http://orcid.org/0000-0002-1299-6488

moraes.ninja@hotmail.com

\section{Viviane Farias Silva (id}

Universidade Federal de Campina Grande, Brasil

http://lattes.cnpq.br/5011520274887172

http://orcid.org/0000-0002-5891-0328

flordeformosur@hotmail.com
Kalyne Sonale Arruda Brito (ic

Universidade Federal do Amapá, Brasil

http://lattes.cnpq.br/4329763474442768

http://orcid.org/0000-0001-9560-1164

line.brito@hotmail.com

Wanessa Alves Martins (iD

Universidade Federal de Campina Grande, Brasil

http://lattes.cnpq.br/4679230808516355

http://orcid.org/0000-0002-2108-2530

wanessamartins.eng@gmail.com
Referencing this:

PEREIRA, J. S.; MORAES NETO, J. M.; SILVA, V. F.; BRITO, K. S. A.; MARTINS, W. A.. Níveis de degradação das terras no município de Taperoá, Paraíba. Revista Ibero Americana de Ciências Ambientais, v.12, n.4, p.66-74, 2021. DOI: http://doi.org/10.6008/CBPC21796858.2021.004.0007 


\section{INTRODUÇÃO}

O Nordeste do Brasil possui uma área de $393.897 \mathrm{~km}^{2}$ enquadrada no nível de degradação ambiental moderado, $81.870 \mathrm{~km}^{2}$ em nível grave e $98.595 \mathrm{~km}^{2}$ em nível muito grave (BRASIL, 2010). Marengo et al. (2011) afirmam que com o início da agricultura que foi expandindo para a região semiárida, grande parte da área era ocupada por enormes fazendas de criação de gado, com uso de pasto nativo, a caatinga com pequenos agricultores com agricultura de subsistência, considerados extremamente vulneráveis as condições ambientais.

No domínio do semiárido, bioma caatinga, é caracterizado baixa pluviometria influenciando o curso dos rios, que secam em determinadas épocas, diminuindo a disponibilidade de água para plantas, animais e para os homens, aumentando a aridez do ambiente. O clima é então um fator determinante na caatinga, definindo a paisagem e os hábitos dos moradores deste bioma. Nesse contexto Chaves et al. (2013), relatam que estudos da vegetação e uso da terra vêm sendo desenvolvidos, com o objetivo de obter informações a partir de imagens de satélite e de outros produtos do sensoriamento remoto, em busca de facilitar a análise e a interpretação dos dados de superfície, para posterior estudo e avaliação buscando melhor aplicação na gestão do município.

A degradação está intimamente ligada à dinâmica das vulnerabilidades verificadas na região, sendo que a pobreza e a vulnerabilidade são condições que se reforçam mutuamente, seguido da deficiência nas políticas públicas, as condições climáticas desfavoráveis e solos de reduzida aptidão agrícola, principalmente quando estes recursos naturais são explorados por métodos insustentáveis do ponto de vista da sua preservação.

Estudos da vegetação e uso da terra vêm sendo pontos de pesquisa, com o objetivo de obter informações a partir de imagens de satélite e de outros produtos do sensoriamento remoto, em busca de facilitar a análise e a interpretação dos dados da superfície terrestre, pois índices de vegetação ressaltam o comportamento espectral de alvos de interesse de diversos ambientes, possibilitando distinguir alterações ao longo de décadas de degradação tanto antrópica, quanto natural. Florenzano (2011), relata que no cenário em que à interferência das ações antrópicas acabam por comprometer a preservação da vegetação, as ferramentas geotecnológicas de monitoramento através de imagens de Sensores Remotos podem ser amplamente utilizadas na análise da degradação vegetal.

Nesse contexto, a realização de pesquisas cientificas sobre a degradação ambiental, sua destruição ou regeneração, associado a vulnerabilidades da população, com o uso de geotecnologias que proporcionam verificar o uso do solo e aumento ou redução dos impactos ambientais em uma área, são fundamentais para a gestão dos recursos naturais e identificação dos fatores que causam a degradação ambiental, bem como para a tomada de decisão das políticas públicas na busca da sustentabilidade ambiental para a preservação do meio ambiente. Assim foi realizado a análise da degradação das terras no município Taperoá - PB utilizando as imagens do satélite Landsat 5 e 8 referentes ao período de 1990 e 2015. 


\section{MATERIAIS E MÉTODOS}

As imagens utilizadas neste trabalho foram adquiridas a partir do Catálogo de Imagens do Instituto Nacional de Pesquisas Espaciais (INPE), disponíveis de forma gratuita no site da instituição. O critério de seleção das imagens baseou-se principalmente na quantidade e distribuição de nuvens da área de estudo, obtidas a partir do satélite TM/Landsat - 5, com data de passagem 14/03/1990, e OLI/Landsat - 8, com data de passagem 06/05/2015, referentes a órbita 215 e ponto 65.

As técnicas de processamento digital de imagens foram divididas em 3 etapas: Pré Processamento de imagens: é o conjunto de processamentos por onde passa as imagens, visando minimizar, ao máximo, suas distorções. Estas distorções podem ser classificadas em radiométricas e geométricas. As distorções radiométricas alteram os níveis de cinza de cada elemento da imagem. Já as distorções geométricas alteram a distribuição espacial dos elementos de imagem, afetando escala, afinidade, orientação, entre outras.

Realce de imagens: está técnica tem por objetivo modificar, através de funções matemáticas os níveis de cinza ou os outros valores digitais de uma imagem, de modo a destacar certas informações espectrais, melhorando a sua qualidade visual e facilitando a análise posterior pelo fotointérprete.

Análise de imagens: está relacionada com a extração de informação de imagens. Inclui a segmentação e classificação de imagens. A segmentação tem por objetivo fragmentar uma região em unidades homogêneas, considerando algumas de suas características intrínsecas, como por exemplo, o nível de cinza dos pixels, textura e contraste. Já a classificação de imagens visa a categorização da cobertura da terra, distinguindo as composições de diferentes materiais superficiais, sendo uma segmentação específica usando técnicas de reconhecimento de padrões.

Os mapas finais das classes de vegetação e dos níveis de degradação das terrasforam criados no módulo SCARTA do software usado, SPRING.

\section{RESULTADOS E DISCUSSÃO}

Os resultados dos níveis de degradação das terras (Figuras 1 e 2) obtido com base em imagens TM/Landsat-5 para o ano de 1990 e OLI/Landsat-8 para o ano de 2015, processadas no SPRING 5.2.7 e complementado com trabalho de campo, apresentado na Tabela 1 evidenciam que a degradação na área de estudo ocorreu variações significativas, caracterizadas por seis níveis de degradação ambiental: muito baixo, baixo, moderado baixo, moderado, moderado grave e grave, além dos níveis foi observado o corpo d'água presente na imagem. Esses níveis de degradação foram estudados por Barbosa et al. (2005), através de várias pesquisas de campo em torno de sub bacias hidrográficas no semiárido do Brasil.

O comportamento dos níveis de degradação das terras, Tabela 1, teve variações significativas durante intervalo da pesquisa, e pode ser observado que os níveis de degradação baixa e moderado baixa tiveram reduções, o que apresenta uma redução nas áreas mais preservadas desta região. No entanto, o nível de degradação muito grave teve total redução e degradação moderada teve aumento significativo, este avanço 
no processo de degradação é consequência do desmatamento para diversos fins, o risco à degradação é evidente. Conforme o Ministério do Meio Ambiente, o melhor caminho para se evitar a desertificação é a prevenção, por meio do uso racional dos recursos naturais, não permitindo que situações extremas se tornem cada vez mais comuns dentro da paisagem diminuindo recursos importantes para sustentabilidade do homem no campo.

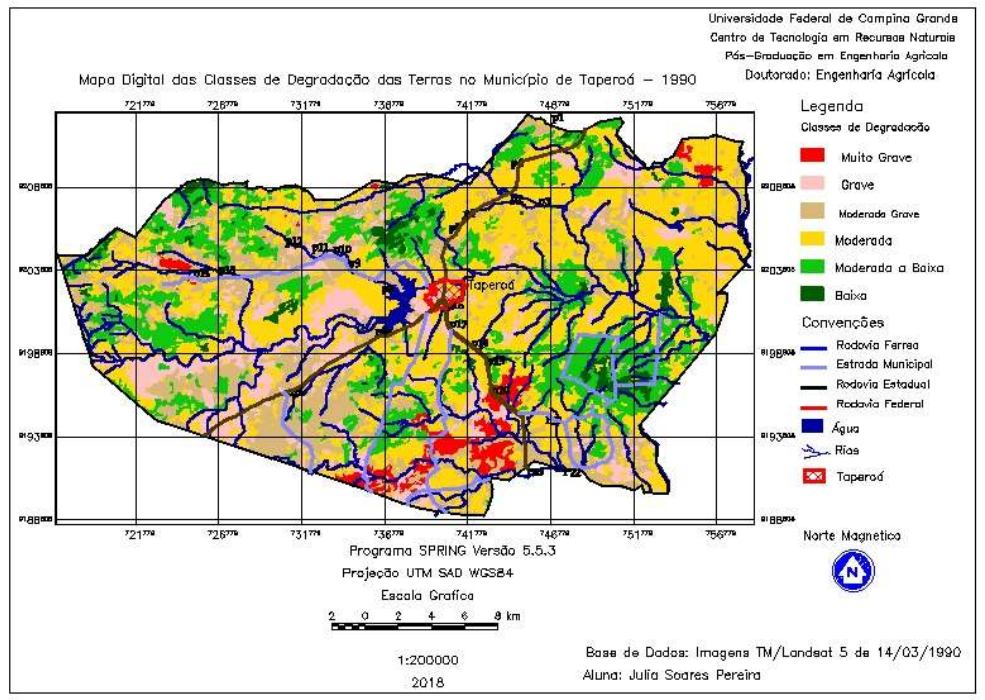

Figura 1: Classes de degradação das terras no município de Taperoá/PB/Brasil, ano 1990.

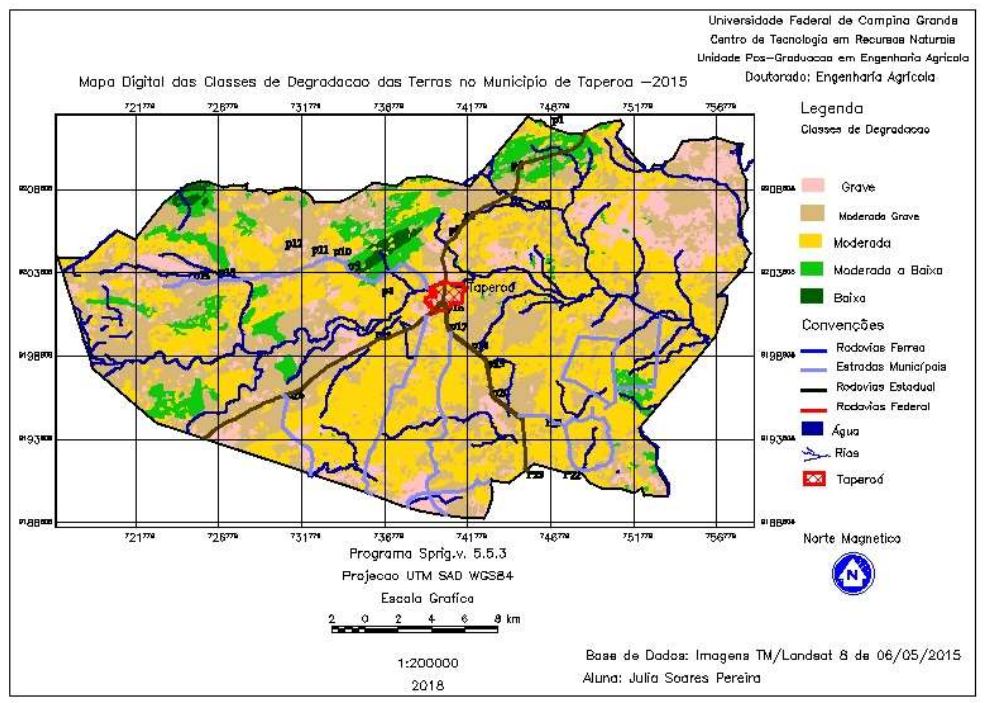

Figura 2: Classes de degradação das terras no município de Taperoá/PB/Brasil, ano 2015.

Tabela 1: Quantificação dos níveis de degradação das terras, no período de 1990 e 2015 no município de Taperoá/PB/Brasil.

\begin{tabular}{lllll}
\hline Níveis de Degradação & $\mathbf{1 9 9 0}$ & $\mathbf{2 0 1 5}$ & Área $\left(\mathrm{km}^{2}\right)$ & \\
\hline & Área $\left(\mathrm{km}^{2}\right)$ & $\%$ & Ál & 0 \\
\hline Degradação Muito Grave & 23,98 & 3,62 & 0,0 & 13,17 \\
\hline Degradação Grave & 87,32 & 13,17 & 87,28 & 38,69 \\
\hline Degradação Moderada Grave & 267,25 & 40,32 & 256,47 & 41,09 \\
\hline Degradação Moderada & 156,11 & 23,55 & 272,35 & 6,37 \\
\hline Degradação Moderada Baixa & 114,21 & 17,23 & 42,23 & 0,63 \\
\hline Degradação Baixa & 10,54 & 1,59 & 4,15 & 0,06 \\
\hline Água (Corpos d'água) & 3,45 & 0,52 & 0,40 & 100 \\
\hline Total & 662,86 & 100 & 662,86 & \\
\hline
\end{tabular}

O nível de degradação muito grave teve seu valor reduzido no ano de 2015 à zero, diminuição 
significativa em relação a 1990, 23,98 km², correspondendo a 3,62\% da área, mostrando que houve recuperação dessas áreas. Essa recuperação foi resultante do abandono das atividades agropecuárias, pois as terras com esse nível são impróprias para a utilização na agropecuária, e com isso os produtores buscam outras áreas e deixam essas abandonadas, havendo assim, uma regeneração lenta (Figura 3).

Constata-se, na mesma tabela que os níveis de degradação grave permaneceu com o mesmo percentual $(13,17 \%)$. Observa-se, ainda que o nível de degradação moderada grave ocupava em 1990, uma área total de $267,25 \mathrm{~km}^{2}(40,32 \%)$ e que com o passar dos anos foi de $256,47 \mathrm{~km}^{2}$ (38,62\%). O nível moderado grave identificado encontra-se em pequena redução.

Nas áreas identificadas, as principais espécies florestais encontradas foram algaroba (Figura 4), malva, xique-xique e mandacaru. Foi possível observar também bastante solo exposto, com aparecimento de sulcos/voçorocas e ausência de matéria orgânica no solo. Os desmatamentos, de forma geral, expõem o solo à maior incidência dos raios solares, inibindo a vida microbiana e propiciando a perda da matéria orgânica. Os desmatamentos causam também a desagregação das gotas de chuva, acelerando o processo de degradação das terras. A área tem uma densidade populacional moderada, mas essa característica demográfica aumenta as possibilidades de modificação da bacia, e praticamente não existem pássaros, pequenos roedores e répteis.

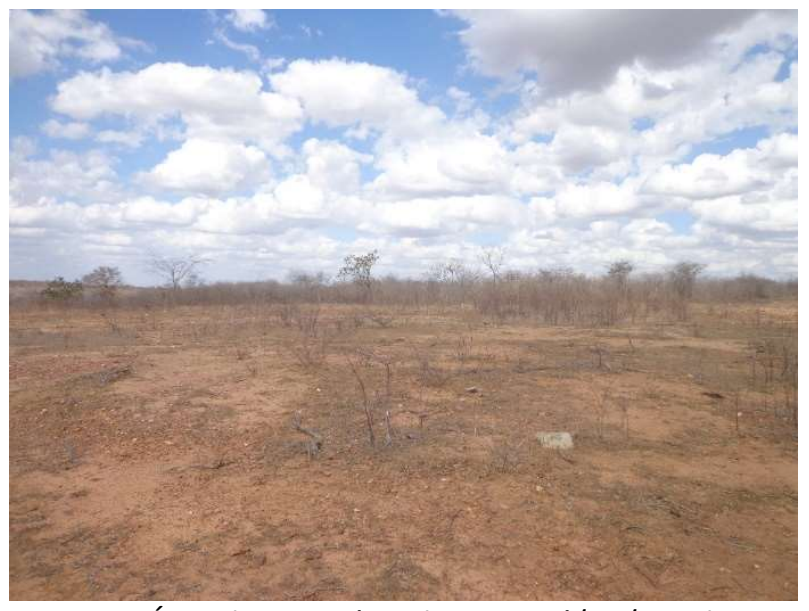

Figura 3: Área do município de Taperoá/PB/Brasil, com característica de redução em nível de degradação.

Fonte: Pereira (2016).

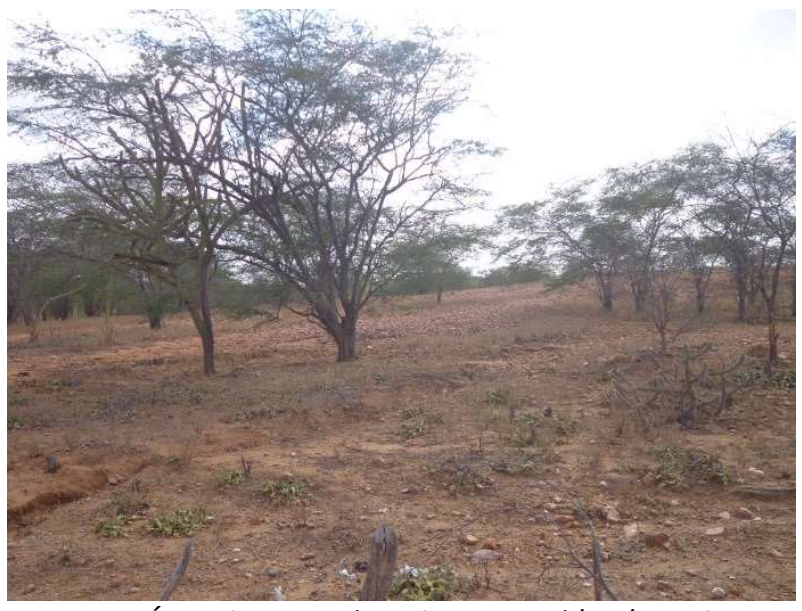

Figura 4: Área do município de Taperoá/PB/Brasil, com presença de algaroba. Fonte: Pereira (2016).

Na degradação grave a vegetação é rala e/ou inexistente, com poucos exemplares de jurema preta, malva, xique-xique e mandacaru. Observou-se a presença de solo exposto, pedregosidade alta e afloramentos de rochas. Além dos problemas já citados com relação aos desmatamentos, ele é responsável também pela redução da infiltração de água no solo, diminuindo a quantidade de água para o abastecimento do lençol freático, que ocasiona o abaixamento do seu nível. Praticamente toda a vegetação nativa foi retirada, sendo a algaroba a única espécie vegetal, isso tem uma explicação, devido esta ser extremamente alelopática, o crescimento de outras espécies vegetais ao seu redor é inibida, prejudicando a alimentação dos animais domésticos nos períodos de entressafra. Além disso, o consumo excessivo do fruto dessa planta causa nos bovinos à doença conhecida como "cara-torta", o que reduz a produtividade do rebanho. Na 
agricultura as espécies mais exploradas são feijão e milho, já na pecuária os mais explorados são bovinos, caprinos e ovinos.

Nas áreas de degradação moderada grave a vegetação é rala e/ou arbustiva, com alguns exemplares de jurema, algaroba, malva, pereiro, xique-xique e mandacaru. Observou-se, também, a presença de solo exposto, com grandes áreas em processo de erosão e pedregosidade alta. Muitos agricultores realizam queimadas para "limpar" os terrenos para o próximo ano, essa prática é realizada sem nenhuma orientação técnica e a maioria dos agricultores não sabe dos malefícios que essas queimadas trazem ao solo. A pecuária extensiva é realizada por grande parte dos agricultores e essa forma de criação compacta os solos e causa erosão. A densidade populacional é de média a alta, e é possível observar pássaros e pequenos roedores.

Houve um aumento da degradação moderada entre as datas analisadas. Nas terras com este nível de degradação, a agricultura é constituída basicamente por feijão e milho. As espécies florestais mais encontradas foram pereiro, malva, algaroba, jurema, juazeiro e marmeleiro. A quantidade de solo exposto é menor do que no nível moderada grave, a densidade populacional é média, e são encontradas aves como o galo de campina, caboclo e golado. Já na pecuária, a caprinovinocultura é a atividade mais realizada pelos agricultores.

Mesmo sabendo da importância socioeconômica da pecuária para a região, essa atividade também gera pressão sobre os recursos naturais. A criação de caprinos, principal atividade da região, pode levar a morte centenas de espécies vegetais, pois, por possuir um hábito alimentar aéreo, chega a roer até as cascas das árvores, destruindo os vasos liberianos, o que leva a interrupção do transporte de seiva bruta e elaborada, e a consequência disso é a morte da planta. Já os bovinos, de peso específico superior até ao de máquinas agrícolas, como de um trator, por exemplo, pode em pouco tempo de pastejo compactar uma determinada área, reduzindo o potencial produtivo da mesma.

Nas áreas com degradação moderada baixa, a densidade populacional observada foi baixa, a vegetação arbustiva é de porte baixo, representada basicamente por jurema, malva, algaroba, marmeleiro e por exemplares isolados de pereiro, aroeira, juazeiro, macambira, coroa de frade, xique-xique e mandacaru. Observou-se ainda ocupação agrícola com milho, feijão, batata-doce e muitas fruteiras: cajueiro, mangueira, goiabeira e coqueiro. Foram encontrados muitos pássaros e insetos.

O nível de degradação baixa ficou caracterizada pela pouca interferência humana. A densidade da vegetação é de média a alta. As espécies vegetais mais encontradas foram pereiro, catingueira, marmeleiro, jurema, algaroba, juazeiro, malva, alecrim, xique-xique, mandacaru, coroa de frade e macambira. Os solos dispõem de muito detrito orgânico, o que reduz a erosão nos períodos de chuva. Atividades como agricultura e pecuária são menos frequentes, a quantidade de aves e répteis é grande.

Já a degradação muito baixa é caracterizada pela pequena densidade populacional. Este nível se encontra nas serras e a preservação se deve a dificuldade de acesso do homem a essas serras. A vegetação é densa, predominante de porte arbustivo, com alguns exemplares arbóreos. Nos topos das serras há grandes extensões de rocha expostas caracterizando áreas de afloramento, ocupadas por espécies típicas, como umbuzeiro, juazeiro, mufumbo, cumaru, jatobá, pereiro, quixabeira, aveloz, catingueira e jurema, além de 
muitas cactáceas e gramíneas. Foi observado uma grande quantidade de pássaros, roedores, répteis e animais de pequeno e médio porte, os solos são conservados e férteis, com muita matéria orgânica.

Na América Latina, vastas áreas se encontram afetadas com diferentes níveis de degradação, onde as principais causas apontadas sob o ponto de vista socioeconômico é a aplicação de modelos de desenvolvimento caracterizados pelo uso não sustentável dos recursos naturais e práticas agrícolas inadequadas (COSTA FILHO, 2005).

O avanço do processo de degradação ambiental do bioma Caatinga deve-se a vários fatores. Parafraseando Costa et al. (2009) e Brasileiro (2009), os principais fatores que contribuem para a degradação desse bioma são: as práticas agrícolas inadequadas, o desmatamento, a infertilidade e a compactação do solo, os processos erosivos e a salinização de algumas áreas.

Segundo Cândido (2000), o desmatamento nas áreas tem provocado sérios problemas de erosão eólica, laminar e hídrica. Com isso, a degradação ambiental das regiões semiáridas está relacionada a uma série de fatores intrínsecos, entre os quais se podem citar a ação antrópica, como consequência direta da falta de sustentabilidade, as altas taxas de evapotranspiração, os baixos índices pluviométricos e o mau uso da terra.

A agricultura é uma atividade que gera impactos ao meio ambiente, seja em grande ou pequena escala; isso dependerá das técnicas e práticas que forem utilizadas para cultivar a terra. As práticas agrícolas ineficientes que retiram a cobertura vegetal original do solo, deixando-o vulnerável aos processos erosivos. O desenvolvimento contínuo dessas práticas, de retirada de produtos sem a reposição de nutrientes, acarreta a perda da fertilidade da terra. Levando em consideração o tipo de solo da região, isso pode intensificar os processos de degradação do bioma. A agricultura irrigada, realizada sem levar em conta as características físicas da localidade, também pode acarretar sérios problemas, como salinização, erosão e lixiviação. O uso de máquinas também pode interferir na boa conservação do solo, pois poderá ocasionar processo de compactação, entre outros (SANTOS, 2009).

A retirada da cobertura original do solo do bioma caatinga é um dos primeiros indicadores dos processos de degradação e desertificação da região, pois, além de interferir nas condições físicas, afeta o desenvolvimento e a manutenção de atividades ligadas ao social, econômico, cultural. Precisa-se urgentemente da implementação de estratégias e de planejamento que visem ao uso racional dos recursos e, consequentemente, à melhoria da qualidade de vida no semiárido. Pode-se dizer que a erosão é um dos problemas mais graves na escala de degradação, porque geralmente provoca impactos irreversíveis ao meio ambiente. No que diz respeito ao Nordeste, mais precisamente ao semiárido, os processos erosivos tornamse preocupantes, já que o solo está cada vez mais vulnerável devido à ação antrópica intensificadora e à própria fragilidade do material pedológico: solos rasos, cascalhentos e muitas vezes areno-argiloso (SÁ et al., 1994).

A salinização tem contribuído bastante para o aumento da degradação do semiárido: “A salinização é um processo que ocorre basicamente pelo acúmulo de sais solúveis e/ou sódio trocável no complexo de troca do solo" (SAMPAIO et al., 2005). A suscetibilidade dos solos à salinização dependerá da água que é 
utilizada na irrigação de lavouras, como também dos tipos e perfis de solos predominantes.

A compactação do solo é ocasionada por práticas de manejo inadequado dos rebanhos, principalmente na pecuária extensiva. Nesse tipo de técnica de criação de animais, geralmente o rebanho fica à solta em grandes extensões de terras sem que os proprietários tenham a preocupação em fazer o rodízio apropriado do pasto. Pode-se afirmar, portanto, que os processos de compactação do solo através de algumas atividades econômicas, como a pecuária, não degradam tanto o meio ambiente local, quanto outras. Porém, embora a pecuária não seja uma atividade das mais prejudiciais ao bioma caatinga, se somada aos demais impactos que a região vem sofrendo, poderá haver um efeito bem mais intenso. A preocupação com o desmatamento e o aceleramento dos processos de degradação do bioma caatinga tem levado pesquisadores, órgãos governamentais, ONGs, setor privado e outros atores sociais a empenharem-se na busca de um desenvolvimento econômico sustentável para a região Nordeste. Foi assim que muitas experiências alternativas surgiram, como a agroecologia, o extrativismo controlado de algumas matériasprimas da caatinga e o turismo ecológico (PRUDÊNCIO et al., 2009).

A necessidade crescente de representação do espaço geográfico e dos fenômenos possibilitou o surgimento de avanços tecnológicos como: a cartografia digital, o sensoriamento remoto (SERE) e o geoprocessamento (SIG's). O que permitiu uma constante análise e sistematização do conhecimento geográfico para o aprimoramento de pesquisas em Geografia, principalmente dentro do âmbito da questão ambiental. A análise de mudanças ambientais ocorridas em uma região somente pode ser amplamente estudada com o emprego de imagens de satélites (SERE) que possibilitam o estudo do espaço ao longo do tempo e também do geoprocessamento (SIG), que permite a aquisição, armazenamento e manipulação de informações de forma rápida e eficiente, proporcionando a tomada de decisões e dirimindo os impactos ambientais (RODRÍGUEZ, 2005).

\section{CONCLUSÕES}

Os resultados apresentados permitem concluir que: - Em relação aos níveis de degradação das terras, houve redução nos níveis de degradação baixa e moderado baixa $\left(6,4 \mathrm{~km}^{2} ; 72,0 \mathrm{~km}^{2}\right)$, o que apresenta uma redução nas áreas mais preservadas da região. No entanto, o nível degradação moderada teve aumento significativo $\left(116 \mathrm{~km}^{2}\right)$, este avanço no processo de degradação é consequência do desmatamento para diversos fins, o risco a uma degradação de nível elevado é evidente.

Em toda a área estudada e pelos relatos da população em mais de 10 anos sem produtividade, muitas áreas foram abandonadas, dando prioridade a agricultura de subsistência, o que mostra o aumento da vegetação semidensa. Já a redução da vegetação que apresenta densidade e o solo mais exposto foram características da exploração da pecuária extensiva, desmatamento, implantação de loteamentos da construção civil e o aumento da densidade demográfica. Essas atividades provocam perdas de biodiversidade, desencadeando processos erosivos e provocando assoreamento dos açudes.

As atividades antrópicas como: utilização inadequada das terras agrícolas, práticas deficientes no manejo de solos e água, desmatamento, remoção da vegetação natural, pastoreio excessivo, rotação 
incorreta de culturas e práticas não conservacionistas contribuíram diretamente na degradação.

\section{REFERÊNCIAS}

BARBOSA, E. I.; NASCIMENTO, S. R.; PORDEUS, R. B.. Percepções da caatinga, um bioma único e exclusivo do semiárido brasileiro. In: WORKSHOP INTERNACIONAL SOBRE ÁGUA NO SEMIÁRIDO BRASILEIRO CAMPINA GRANDE - PB, 1. Anais. 2005.

BRASILEIRO, R. S.. Alternativas de Desenvolvimento Sustentável no Semiárido Nordestino: da Degradação à Conservação. Scientia Plena, v.5, n.5, 2009.

BRASIL. Ministério do Meio Ambiente. Monitoramento dos biomas brasileiros por satélite acordo de cooperação técnica MMA/IBAMA. Monitoramento do Bioma Caatinga 2002 a 2008. Centro de Sensoriamento Remoto CSR/IBAMA. Brasília: MMA/IBAMA, 2010.

CÂNDIDO, H. G.. Avaliação da degradação ambiental de parte do Seridó Paraibano. Dissertação (Mestrado em Engenharia Agrícola) - Universidade Federal da Paraíba, Campina Grande, 2000.

COSTA, T. C. C.; OLIVEIRA, M. A. J.; ACCIOLY, L. J. O.; SILVA, F. H. B. B... Análise da Degradação da Caatinga no Núcleo de Desertificação do Seridó. Revista Brasileira de Engenharia Agrícola e Ambiental, v.13, p.961-974, 2009. DOI: https://doi.org/10.1590/S1415-43662009000700020

COSTA FILHO, J. F.. Avaliação dos componentes do balanço de energia e evapotranspiração em região semiárida usando imagens orbitais landsat-5 TM e terra-MODIS. Dissertação (Mestrado em Recursos Naturais) - Universidade Federal de Campina Grande, Campina Grande, 2005.

CHAVES, I. B.; FRANCISCO, P. R. M.; LIMA, E. R. V.; SILVA, B. B.; BRANDÃO, Z. N.; CHAVES, L. H. G.. Índices espectrais, diagnóstico da vegetação e degradação da caatinga na Bacia do Rio Taperoá-PB. In: SILVA, B. B.. Aplicações brasileiras de geoprocessamento e sensoriamento remoto. Campina Grande: EDUFCG, 2013. p.23-47.

FLORENZANO, T. G.. Imagens de satélite para estudos ambientais. São Paulo, Oficina de Texto, 2011.

MARENGO, J. A.; ALVES, L. M.; BESERRA, E. A.; LACERDA, F. F.. Variabilidade e mudanças climáticas no semiárido brasileiro. In: RECURSOS HÍDRICOS EM REGIÕES ÁRIDAS E SEMIÁRIDAS. Anais. 2011. p.383-422.

PRUDÊNCIO, M. A.; CÂNDIDO, D. K.. Degradação da vegetação nativa do município de Assú/RN: indicadores e ações mitigadoras. Sociedade e Território, Natal, v.21, n.1-2, p.144 -156, 2009.

RODRÍGUEZ, A. C. M.. Sensoriamento Remoto e Geoprocessamento Aplicados na Análise da Legislação Ambiental no Município de São Sebastião (SP). Dissertação (Mestrado) - Universidade de São Paulo, São Paulo, 2005.

SAMPAIO, E. V. S. B.; ARAÚJO, M. S. B.. Desertificação no Nordeste do Brasil. In: CONGRESSO BRASILEIRO DE CIÊNCIA DO SOLO. Anais. 2005.

SANTOS, L. L.. Quantificação do escoamento superficial e erosão do solo em regiões semiáridas. Revista Brasileira de Geografia Física, Recife, v.2, n.1, p.14-25, 2009.

SÁ, T. F. F.; COSTA FILHO, J. F.; FRANCISCO, P. R. M.; BRAGA JÚNIOR, J. M.. Sistema de Informações Geográficas (SIG) para a gestão ambiental de bacias hidrográficas. In: SIMPÓSIO BRASILEIRO DE CIÊNCIAS GEODÉSICAS E TECNOLOGIAS DA GEOINFORMAÇÃO. Anais. Recife, 2010. p.001-004.

A CBPC - Companhia Brasileira de Produção Científica (CNPJ: 11.221.422/0001-03) detém os direitos materiais desta publicação. Os direitos referem-se à publicação do trabalho em qualquer parte do mundo, incluindo os direitos às renovações, expansões e disseminações da contribuição, bem como outros direitos subsidiários. Todos os trabalhos publicados eletronicamente poderão posteriormente ser publicados em coletâneas impressas sob coordenação da Sustenere Publishing, da Companhia Brasileira de Produção Científica e seus parceiros autorizados. Os (as) autores (as) preservam os direitos autorais, mas não têm permissão para a publicação da contribuição em outro meio, impresso ou digital, em português ou em tradução. 